FACTA UNIVERSITATIS

Series: Mechanical Engineering Vol. 14, N ${ }^{\mathrm{o}}$ 1, 2016, pp. 89 - 99

Original scientific paper

\title{
A STUDY OF THIN FILM LUBRICATION AT NANOSCALE FOR A FERROFLUID BASED INFINITELY LONG ROUGH POROUS SLIDER BEARING
}

\author{
UDC 532:621.8
}

\author{
Jimit R. Patel, Gunamani Deheri \\ Department of Mathematics, Sardar Patel University, India
}

\begin{abstract}
The study aims at analyzing the performance of a ferrofluid-based infinitely long rough porous slider bearing which makes use of thin film lubrication at nanoscale. The stochastic model of Christensen and Tonder has been employed to analyze the effect of surface roughness while the Neuringer-Rosensweig's model has been adopted to study the magnetization effect. The pressure distribution in the bearing system has been obtained by solving the associated stochastically averaged Reynolds type equation. The results indicate that although the transverse roughness is supposed to affect the bearing system adversely, the situation remains fairly better in the case of thin film lubrication at nanoscale. In fact, the consideration of thin film lubrication at nanoscale results in an all round improved performance, even for lower strength of the magnetic intensity. However, the couple stress adds a little more to this positive effect.
\end{abstract}

Key Words: Long Bearing, Ferrofluid, Rough Surfaces, Nanoscale, Load-carrying Capacity

\section{INTRODUCTION}

The squeeze film phenomena develop when two surfaces approach each other at a normal velocity. Due to the noticeably good behavior of the squeeze film, it is often used in different fields of real life such as machine tools, gears, rolling elements, hydraulic systems, engines, clutch plates, etc.

Nowadays, quite a great number of theoretical and experimental inventions are made on the bearing design systems as well as on the lubricating substances in order to enhance the efficiency of the bearing performances. One of the major inventions is the use of ferrofluid as a lubricant in the bearing systems. Many authors (Rosensweig [1], Popa et al.

Received November 5, 2015 / Accepted February 14, 2016

Corresponding author: Jimit Patel

Department of Mathematics, Sardar Patel University,Vallabh Vidyanagar, Anand, Gujarat India-388120

E-mail: patel.jimitphdmarch2013@gmail.com 
[2], Nada and Osman [3], Urreta et al. [4], Huang et al. [5], Patel et al. [6]) have discussed the performance and applications of ferrofluids in different bearing systems. These investigations established that the bearing performance characteristics are enhanced due to the magnetic fluid effects.

Another major invention has been made in the research of thin film lubrication. Since 1990s, the thin film lubrication has been well discussed as a new lubrication regime. The transition from the thin film lubrication to the boundary one, the transition from the elastohydrodynamic lubrication to the thin film lubrication, the failure of liquid film at nanoscale and the mechanism of the thin film lubrication were analyzed by Luo [7], Luo et al. [8], and Luo and Wen [9]. Shen et al. [10] studied the performance of liquid crystal additives in the construction of thin film. Zhang et al. [11] investigated the thin film lubrication characteristics in two phase fluid. It was found that the existence of couple stress enhanced the load carrying capacity.

The study of roughness, which develops after some run-in and wear, remains of primary concern for designing the bearing system and the bearing system failure. Christensen and Tonder [12-14] proposed a more general method of studying the performance of both the roughness patterns (transverse as well as longitudinal). Gupta and Deheri [15] deployed the method of Christensen and Tonder to analyze the performance of a rough spherical bearing. Chiang et al. [16] theoretically discussed the combined effect of couple stresses and surface roughness on the instability thresholds of a rough short journal bearing lubricated with non-Newtonian fluids by adopting the theory of Christensen and Tonder. In their study, the couple stress escorted with longitudinal roughness to provide an increase in the stability threshold speed. On the ground of Christensen and Tonder's results, Patel and Deheri [17] investigated the characteristics of lubrication at nanoscale on the performance of a transversely rough slider bearing. It was observed that the load carrying capacity increases due to the thin film lubrication at nanoscale and the existence of couple stress. Deresse and Sinha [18] dealt with a thermal and roughness effect on different characteristics of the finite rough tilted pad slider bearings. It was established that for non-parallel slider bearings the load carrying capacity due to the combined effect was less than the load capacity due to roughness effect for both the roughness models. Vakis and Polycarpou [19] developed a model to study the mixed nano lubrication regime expected during light contact or "surfing", recording in magnetic storage. In fact, they investigated an advanced rough surface continuum based contact and sliding model in the presence of a molecularly thin lubricant. Patel and Deheri [20] dealt with the effect of various porous structures on the Shliomis model based ferrofluid lubrication of the thin film squeezed between the rotating rough curved circular plates. It was established that the Kozeny-Carman's model remained more suitable for bearing design as compared to the Irmay's one. Further, the Shliomis model based ferrofluid lubrication performed relatively better than the Neuringer-Rosensweig one. Patel and Deheri [21] analyzed the effect of transverse surface roughness on the behavior of a magnetic fluid based short bearing considering thin film lubrication at nanoscale. It was observed that the thin film lubrication at nanoscale led to a sustained improvement in bearing performance characteristics even for lower values of magnetization parameter.

The aim of the present study is to analyze the performance characteristics of a magnetic fluid based rough long bearing considering the thin film lubrication at nanoscale. 


\section{ANALYSIS}

The geometrical configuration of the bearing system is presented in Fig. 1. The bearing system is infinite in $z$ direction. The slider moves with uniform velocity $u$ in $x$ direction. The length of the bearing is $L$ and the breadth $B$ is in $z$ direction.

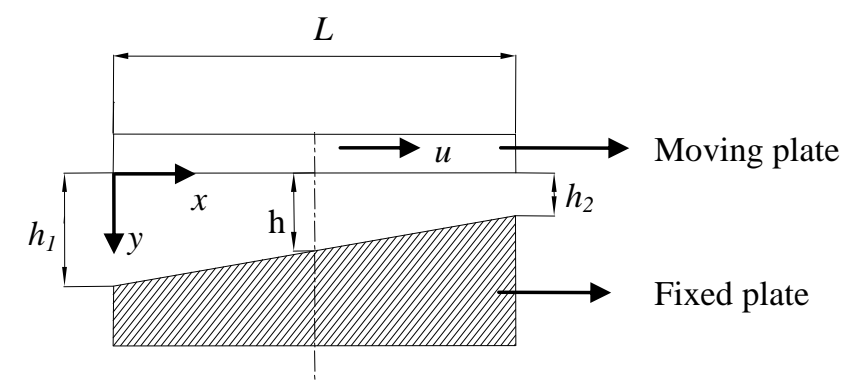

Fig. 1 Configuration of the bearing system

The bearing surfaces are considered to be transversely rough. In view of the study of Christensen and Tonder [12-14], thickness $\mathrm{h}(\mathrm{x})$ of the lubricant film is taken as

$$
\mathrm{h}(\mathrm{x})=\overline{\mathrm{h}}(x)+h_{s}
$$

where $\overline{\mathrm{h}}(\mathrm{x})$ represents the mean film thickness and $h_{s}$ denotes the deviation from the mean film thickness characterizing the random roughness of the bearing surfaces. Deviation $h_{s}$ is considered to be stochastic in nature and governed by the probability density function:

$$
f\left(h_{s}\right)=\left\{\begin{array}{c}
\frac{35}{32 c}\left(1-\frac{h_{s}^{2}}{c^{2}}\right)^{3},-c \leq h_{s} \leq c \\
0, \quad \text { elsewhere }
\end{array}\right.
$$

where $c$ denotes the maximum deviation from the mean film thickness. Mean $\alpha$, standard deviation $\sigma$ and parameter $\varepsilon$, which is the measure of symmetry of random variable $h_{s}$, are defined by the relationships as discussed by Christensen and Tonder [12-14]. The details are dealt with there in.

The magnetic field is oblique to the stator as taken by Agrawal [22]. More details of on the effect of various forms of magnitude of the magnetic field have been incorporated by Prajapati [23], Bhat [24] and Patel and Deheri [25]. According to these discussions, the magnitude of the magnetic field is considered as:

$$
M^{2}=k L^{2} \frac{x}{L} \sin \left(1-\frac{x}{L}\right),
$$

where $k$ is a suitably chosen constant from dimensionless point of view (Bhat [24]), so as to produce a magnetic field of required strength.

Under the usual assumptions of hydrodynamic lubrication the related stochastically averaged Reynolds equation (Bhat [24], Prajapati [23], Luo et al. [26], Patel and Deheri $[27,28])$ takes the form: 


$$
\frac{d}{d x}\left(p-\frac{\mu_{0} \bar{\mu} M^{2}}{2}\right)=6 \mu u \frac{h-h_{m}}{g(h) \phi(\gamma)}
$$

where $h=h_{2}\left\{1+m\left(1-\frac{x}{L}\right)\right\}, m=\frac{h_{1}-h_{2}}{h_{2}}, C=\sqrt{\eta} / \mu, \gamma=h / C, \phi(\gamma)=1-\frac{12}{\gamma^{2}}+\frac{44}{\gamma^{3}}$

and

$$
g(h)=h^{3}+3 h^{2} \alpha+3\left(\sigma^{2}+\alpha^{2}\right) h+3 \sigma^{2} \alpha+\alpha^{3}+\varepsilon,
$$

while $C$ represents the characteristic length which contributes to the couple stress effect, $p$ is film pressure $\mu_{0}$ denoting the magnetic susceptibility, $\bar{\mu}$ is the free space permeability, $\mu$ being the lubricant viscosity and $\eta$ is the material constant responsible for couple stress effect.

The associated boundary conditions are $p=0$ at $x=0$ and $x=L$.

The dimensionless quantities are as following:

$$
\begin{gathered}
H=\frac{h}{\Delta h}, H_{m}=\frac{h_{m}}{\Delta h}, h_{m}=\lambda h_{2}, X=\frac{x}{L}, P=\frac{(\Delta h)^{3}}{\mu u L^{2}} p, \mu^{*}=\frac{(\Delta h)^{3} k \mu_{0} \bar{\mu}}{\mu u}, \\
X=\frac{x}{L}, \bar{\sigma}=\frac{\sigma}{\Delta h}, \bar{L}=\frac{L}{\Delta h}, \bar{\alpha}=\frac{\alpha}{\Delta h}, \bar{\varepsilon}=\frac{\varepsilon}{(\Delta h)^{3}}, G(H)=\frac{g(h)}{(\Delta h)^{3}}
\end{gathered}
$$

where $\Delta h$ is infinitesimal increment in the thickness and $\lambda$ being a film thickness ratio. Making use of the above said boundary conditions, the dimensionless pressure distribution is obtained as:

$$
P=\frac{\mu^{*}}{2} X \sin (1-X)+\frac{6}{\bar{L}} \int_{0}^{X} \frac{H-H_{m}}{G(H) \phi(\gamma)} d X
$$

The non-dimensional load carrying capacity of the bearing system, one can find as:

$$
W=\frac{(\Delta h)^{3}}{\mu u L^{4}} w=\int_{0}^{1} P d X=\frac{\mu^{*}}{2}(1-\sin (1))+\frac{6}{\bar{L}} \int_{0}^{1} \frac{H-H_{m}}{G(H) \phi(\gamma)} d X
$$

where $w=p L B$ is the load carrying capacity.

\section{RESULTS AND DISCUSSIONS}

The linearity of the expression in Eq. (6) with respect to the magnetization parameter suggests that an increase in the magnetization would lead to an increased load carrying capacity.

It is also seen that the load carrying capacity increases by $\mu^{*}(1-\sin (1)) / 2$ as compared to the traditional lubricant based bearing system. This is due to the fact that the viscosity of the lubricant gets increased due to magnetization. The effect of film thickness parameter $H_{m}$ on the load carrying capacity presented in Figs. 2-6 as well as Table 1 make it clear that the load carrying capacity decreases as $H_{m}$ increases. This decrease being more in the case of variance associated with roughness. It is interesting to note that the load carrying capacity increases with increase in the standard deviation associated with roughness. However, the effect of variance on the load carrying capacity with respect to $H_{m}$ is not that sharp. 
A Study on the Thin Film Lubrication at Nano Scale for a Ferrofluid Based Infinitely Long Rough Porous... 93

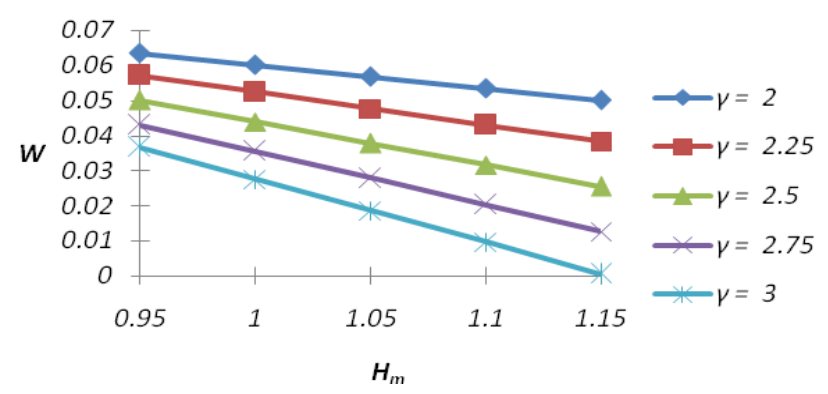

Fig. 2 Variation of load carrying capacity with respect to $H_{m}$ and $\gamma$

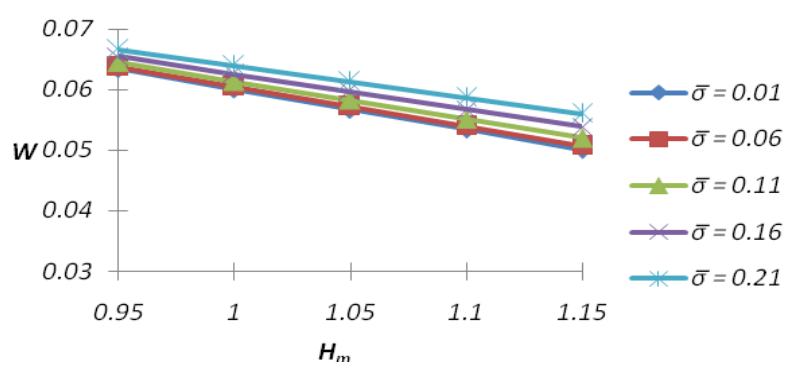

Fig. 3 Variation of load carrying capacity with respect to $H_{m}$ and $\bar{\sigma}$

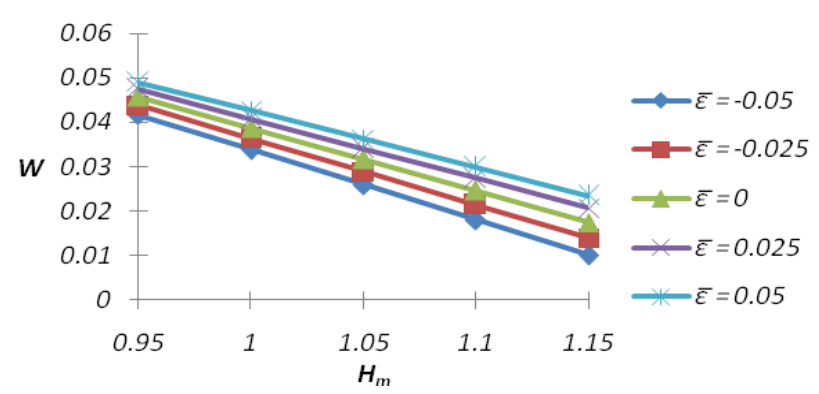

Fig. 4 Variation of load carrying capacity with respect to $H_{m}$ and $\bar{\varepsilon}$

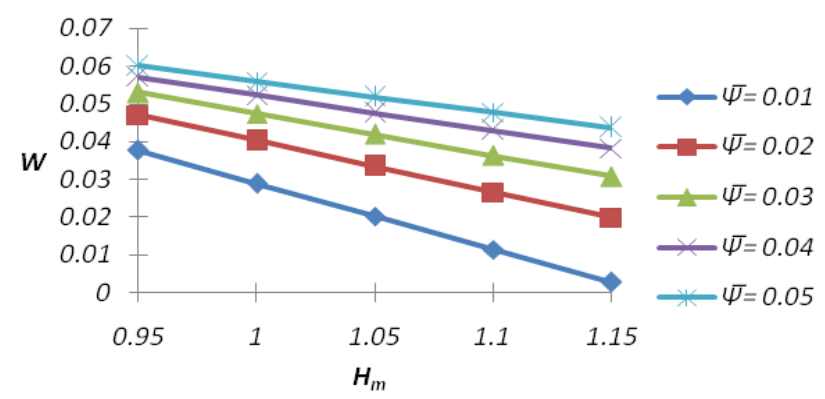

Fig. 5 Variation of load carrying capacity with respect to $H_{m}$ and $\bar{\psi}$ 


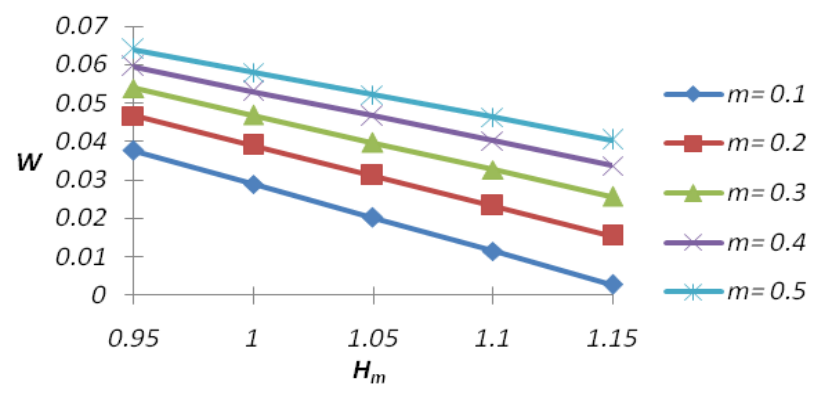

Fig. 6 Variation of load carrying capacity with respect to $H_{m}$ and $m$

Table 1 Variation of load carrying capacity with respect to $H_{m}$ and $\bar{\alpha}$

\begin{tabular}{llllll}
\hline $\mathrm{W}$ & $H_{m}=0.95$ & $H_{m}=1.00$ & $H_{m}=1.05$ & $H_{m}=1.10$ & $H_{m}=1.15$ \\
\hline $\bar{\alpha}=-0.01$ & 0.037685 & 0.028927 & 0.020168 & 0.011410 & 0.002652 \\
$\bar{\alpha}=-0.005$ & 0.038416 & 0.029812 & 0.021207 & 0.012603 & 0.003998 \\
$\bar{\alpha}=0$ & 0.039132 & 0.030678 & 0.022224 & 0.013771 & 0.005317 \\
$\bar{\alpha}=0.005$ & 0.039833 & 0.031527 & 0.023220 & 0.014914 & 0.006607 \\
$\bar{\alpha}=0.01$ & 0.040519 & 0.032357 & 0.024195 & 0.016033 & 0.007871 \\
\hline
\end{tabular}

Figs. 7-10 and Table 2 dealing with the influence of characteristic length suggest that the effect of couple stress is to enhance the load carrying capacity. However, the effect of variance on the load carrying capacity with respect to characteristic length is at the best nominal. The profile of augmented load due to standard deviation is given in Figs. 11-14. It is appealing to note that here even the porosity increases the load carrying capacity when thickness is considered at nanoscale for the long bearing system.

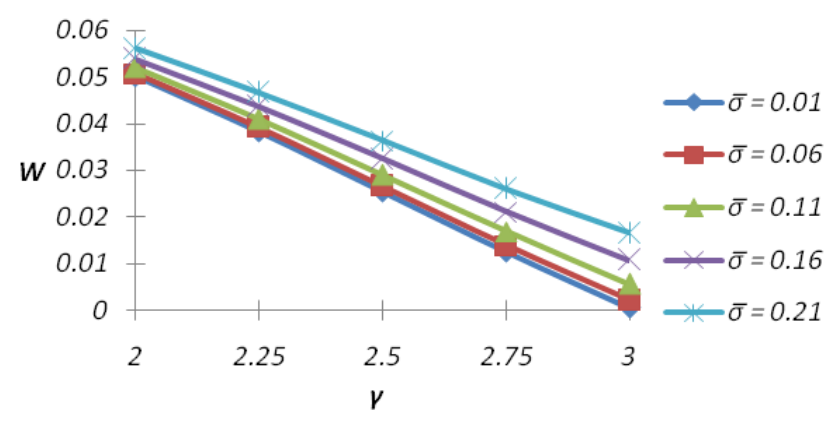

Fig. 7 Variation of load carrying capacity with respect to $\gamma$ and $\bar{\sigma}$ 


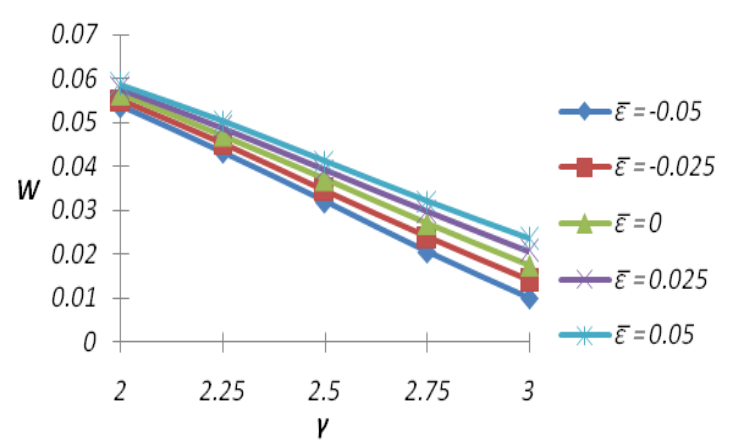

Fig. 8 Variation of load carrying capacity with respect to $\gamma$ and $\bar{\varepsilon}$

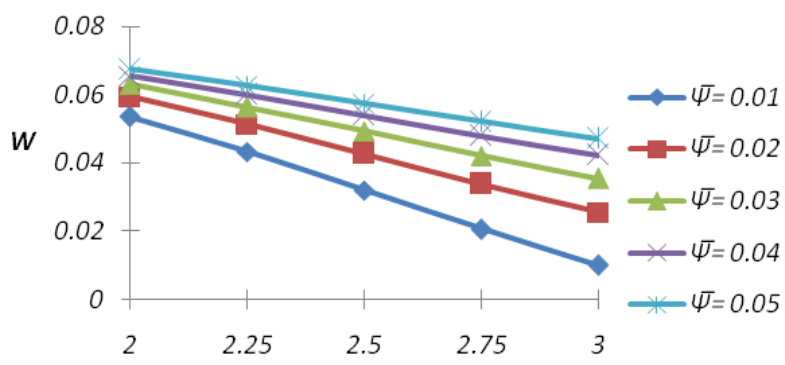

Fig. 9 Variation of load carrying capacity with respect to $\gamma$ and $\bar{\psi}$

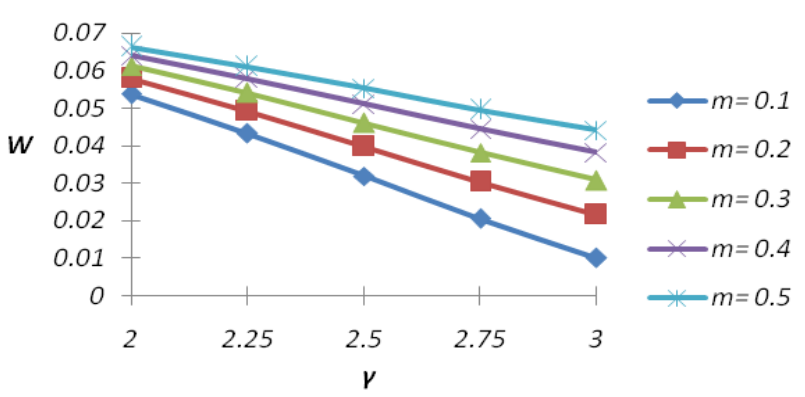

Fig. 10 Variation of load carrying capacity with respect to $\gamma$ and $m$

Table 2 Variation of load carrying capacity with respect to $\gamma$ and $\bar{\alpha}$

\begin{tabular}{lccccc}
\hline $\mathrm{W}$ & $\gamma=2.0$ & $\gamma=2.25$ & $\gamma=2.5$ & $\gamma=2.75$ & $\gamma=3$ \\
\hline $\bar{\alpha}=-0.01$ & 0.053634 & 0.043273 & 0.031951 & 0.020592 & 0.010063 \\
$\bar{\alpha}=-0.005$ & 0.054084 & 0.043906 & 0.032783 & 0.021623 & 0.011279 \\
$\bar{\alpha}=0$ & 0.054525 & 0.044525 & 0.033597 & 0.022633 & 0.012470 \\
$\bar{\alpha}=0.005$ & 0.054957 & 0.045132 & 0.034394 & 0.023621 & 0.013636 \\
$\bar{\alpha}=0.01$ & 0.055380 & 0.045725 & 0.035174 & 0.024589 & 0.014777 \\
\hline
\end{tabular}


Also, equally interesting is the fact that the effects of variance and skewness on the load carrying capacity run approximately opposite to the usual film thickness considered for magnetic fluid lubrication. Probably, this may be happening due to the characteristics of nanoscale film thickness.

The positive effect of variance gets enhanced due to the positively skewed roughness which can be seen in Figs. 15-17. The fact that the aspect ratio introduces a strong impact on the load carrying capacity, when considered with respect to porosity at the nanoscale film thickness, is presented in Fig. 18.

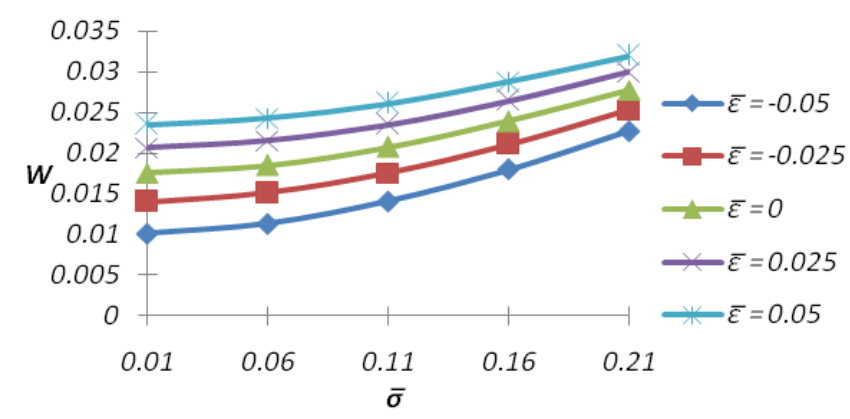

Fig. 11 Variation of load carrying capacity with respect to $\bar{\sigma}$ and $\bar{\varepsilon}$

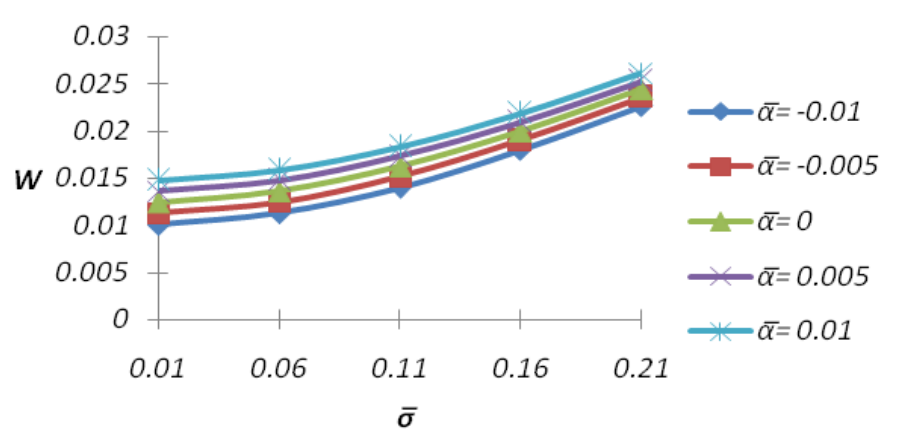

Fig. 12 Variation of load carrying capacity with respect to $\bar{\sigma}$ and $\bar{\alpha}$

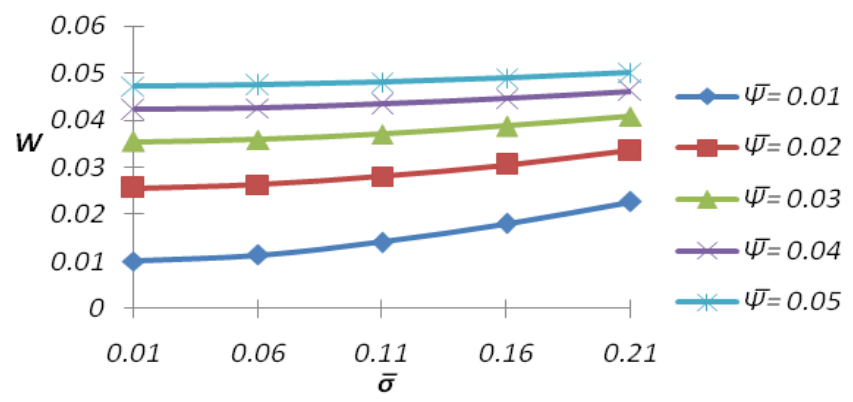

Fig. 13 Variation of load carrying capacity with respect to $\bar{\sigma}$ and $\bar{\psi}$ 
A Study on the Thin Film Lubrication at Nano Scale for a Ferrofluid Based Infinitely Long Rough Porous... 97

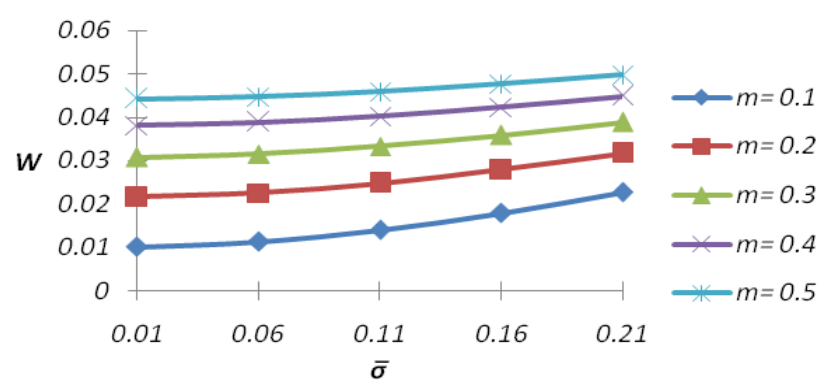

Fig. 14 Variation of load carrying capacity with respect to $\bar{\sigma}$ and $m$

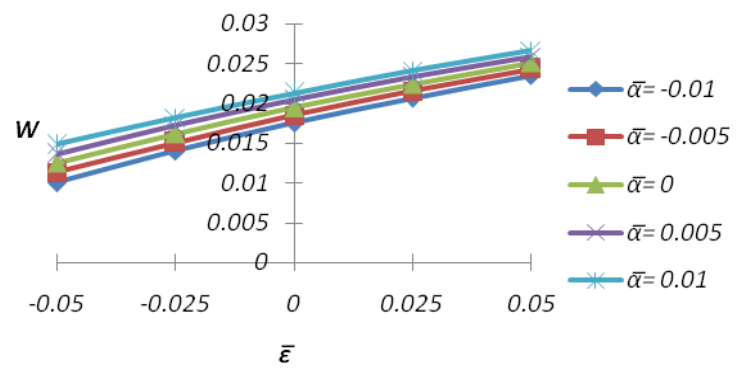

Fig. 15 Variation of load carrying capacity with respect to $\bar{\varepsilon}$ and $\bar{\alpha}$

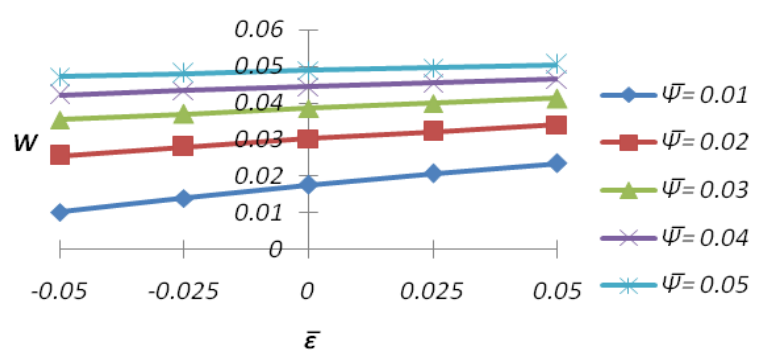

Fig. 16 Variation of load carrying capacity with respect to $\bar{\varepsilon}$ and $\bar{\psi}$

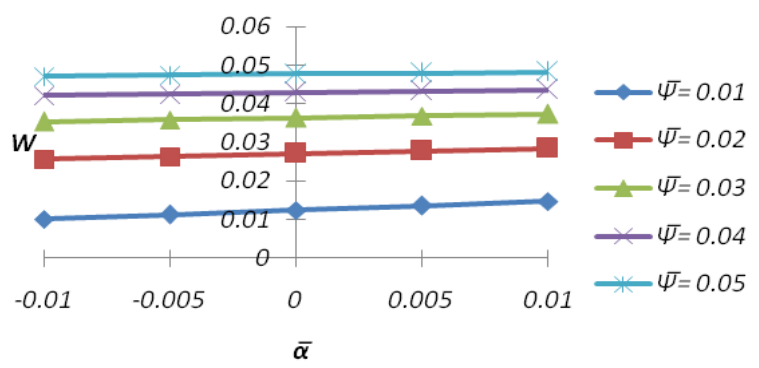

Fig. 17 Variation of load carrying capacity with respect to $\bar{\alpha}$ and $\bar{\psi}$ 


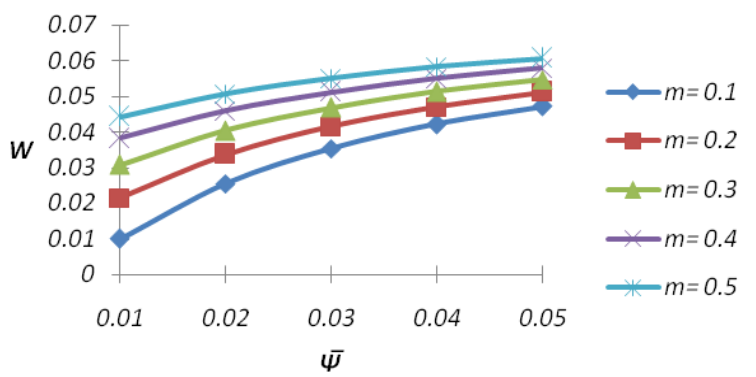

Fig. 18 Variation of load carrying capacity with respect to $\bar{\psi}$ and $m$

Some of the figures presented above indicate that there are various parameters bound to increase the load carrying capacity and therefore, probably, this may turn out to be a very useful and effective bearing system from industry point of view

It is surprising to see the effect of porosity in increasing the load carrying capacity, when the thin film lubrication is considered at nanoscale.

Lastly, a comparison of current investigation with the observation of Patel and Deheri [21] indicates that the load carrying capacity enhances by around 18-20\% when thin film lubrication is considered at a nanoscale. Also, it is clear that here the two roughness parameters, skewness and variance, affect the performance more sharply.

\section{CONCLUSION}

The results presented here suggest that this type of bearing system may be selected for a long run because here even the porosity tends to increase the load carrying capacity which is starkly different from the usual behavior of porosity on other bearing systems. In general, the situation remains better in the case of positively skewed roughness even if the couple stress effect is nominal. This investigation further reveals that the magnetization may provide a suitable measure for an enhanced performance when the thin film lubrication is considered at nanoscale. Even the positive effect of standard deviation may be channelized to good use.

\section{REFERENCES}

1. Rosensweig. R.E., 1985, Ferrohydrodynamics, Cambridge University Press, New York

2. Popa, N.C., Potencz, I., Brostean, L., Vekas, L., 1997, Some applications of inductive Transducers with magnetic fluids, Sensors and Actuators A, 59, pp. 197-200.

3. Nada, G.S., Osman, T.A., 2007, Static performance of finite hydrodynamic journal bearings lubricated by magnetic fluids with couple stresses, Tribol. Lett., 27, pp. 261-268.

4. Urreta, H., Leicht, Z., Sanchez, A., Agirre, A., Kuzhir, P., Magnac, G., 2009, Hydrodynamic bearing lubricated with magnetic fluids, Journal of Physics: Conference series, 149(1), Article ID 012113.

5. Huang, W., Shen, C., Liao, S., Wang, X., 2011, Study on the ferrofluid lubrication with an external magnetic field, Tribology Lett., 41, pp. 145-151.

6. Patel, N.S., Vakharia, D.P., Deheri, G.M., 2012, A Study on the Performance of a Magnetic-FluidBased Hydrodynamic Short Journal Bearing, ISRN Mechanical Engineering, 2012, Article ID 603460. 
7. Luo, J.B., 1994, On Experimental Technique and Characteristic of Thin Film Lubrication, Tsinghua University Doctor Dissertation.

8. Luo, J.B., Wen, S.Z., Huang, P., 1996, Thin film lubrication, Part 1: The transition between EHL and thin film lubrication, Wear, 194, pp. 107-115.

9. Luo, J.B., Wen, S.Z. 1997, The transition between elastohydro-dynamic lubrication and boundary lubrication, $1^{\text {st }}$ World Tribology Conference (ed. Hutchings, I. M.), London: Mechanical Engineering Publication, pp. 9-14

10. Shen, M.W., Luo, J.B., Wen, S.Z., 2001, Nano-tribological properties and mechanisms of the liquid crystal as an additive, Chinese Science Bulletin, 46(14), pp.1227-1232.

11. Zhang, C., Wan, S., and Luo, J., 2002, Characteristic of lubrication at nano scale in two-phase fluid system, Science in China, 45(2), pp.166-172.

12. Christensen, H., Tonder, K.C., 1969a, Tribology of rough surfaces: stochastic models of hydrodynamic lubrication, SINTEF, Report No.10 pp. 69-18.

13. Christensen, H., Tonder, K.C., 1969b, Tribology of rough surfaces: parametric study and comparison of lubrication models, SINTEF, Report No.22 pp. 69-18.

14. Christensen, H., Tonder, K.C., 1970, The hydrodynamic lubrication of rough bearing surfaces of finite width, ASME-ASLE Lubrication Conference, Cincinnati. OH. Paper no. 70-lub-7, October 12-15.

15. Gupta, J.L., Deheri, G.M., 1996, Effect of Roughness on the Behavior of Squeeze Film in a Spherical Bearing, Tribology Transactions, 39, pp. 99-102.

16. Chiang, H.L., Hsu, C.H., Lin, J.R., 2004, Lubrication performance of finite journal bearings considering effects of couple stresses and surface roughness, Tribology International, 37(4), pp. 297-307.

17. Patel, H.C., Deheri, G.M., 2009, Characteristics of lubrication at nano scale on the performance of transversely rough slider bearing, Mechanika, 6(80), pp. 64-71.

18. Deresse, G.A., Sinha, P., 2011, THD analysis for finite slider bearing with roughness: special reference to load generation in parallel sliders, Acta Mech., 222, pp. 1-15,.

19. Vakis, A.I., Polycarpou, A.A., 2013, An Advanced Rough Surface Continuum-Based Contact and Sliding Model in the Presence of Molecularly Thin Lubricant, Tribology Letters, 49(1), pp. 227-238.

20. Patel, J.R., Deheri, G.M.., 2014, Effect of various porous structures on the shliomis model based ferrofluid lubrication of the film squeezed between rotating rough curved circular plates, Facta Universitatis, series: Mechanical Engineering, 12(3), pp. 305-323

21. Patel, J.R., Deheri, G.M., 2015, On the Performance Characteristics of Rough Short Bearing Considering Thin Film Lubrication at Nano Scale, International Journal of Materials Lifetime, 2(1), pp. 44-50.

22. Agrawal, V.K., 1986, Magnetic fluid based porous inclined slider bearing, Wear, 107, pp. 133-139.

23. Prajapati, B.L., 1995, On Certain Theoretical Studies in Hydrodynamic and Electro-magneto hydrodynamic Lubrication, PhD thesis, S.P. University, Vallabh Vidyanagar, Gujarat, India.

24. Bhat, M.V., 2003, Lubrication with a Magnetic fluid, Team Spirit (India) Pvt. Ltd.

25. Patel, J.R., Deheri, G.M., 2014, Slip Velocity and Roughness Effect on Magnetic Fluid Based Infinitely Long Bearings, Proceedings of International Conference on Advances in Tribology and Engineering Systems Lecture Notes in Mechanical Engineering, Springer India, pp. 97-109.

26. Luo, J.B., Qian, L.M., Wen, S.Z., 1999, The failure of fluid at nano-scale, STLE. -Tribology Trans., 42(4), pp. 912-916.

27. Patel, J.R., Deheri, G.M., 2013, A Comparison of Porous Structures on the Performance of a Magnetic Fluid Based Rough Short Bearing, Tribology in Industry, 35(3), pp. 177-189.

28. Patel, J.R., Deheri, G.M., 2015, A Comparison of Different Porous Structures on the Performance of A Magnetic Fluid Based Double Porous Layered Rough Slider Bearing, International Journal of Materials Lifetime, 1(1), pp. 29-39. 